\title{
Comentario de libros
}

\section{La sociología, un apoyo para la interpretación del Nuevo Testamento}

Bengt Holmberg, Historia social del cristianismo primitivo. La socıología y el Nuevo Testamento, Ediciones El Almendro, Córdoba, 1995, 220 páginas.

Creer en Jesús hoy requiere hacer un recorrido y una experiencia de su seguimiento en la vida cotidiana, asumiendo sus opciones fundamentales entendidas correctamente desde nuestros contextos. Pero la fe cristiana tiene que crecer de manera que vaya acompañada por una formación teológica, bíblica, ética y, más aún, remitiéndonos a conocer las raíces históricas y sociológicas de esa misma fe cristiana, en la medida de lo posible.

El texto Historia social del cristianismo primitivo. La sociología y el Nuevo Testamento, del autor Bengt Holmberg, es una contribución más al conocimiento del cristianismo primitivo desde una perspectiva sociológica. Esta obra contiene dos partes fundamentales: a) presenta algunos trabajos de investigación sobre el Nuevo Testamento, realizados durante los años setenta y ochenta, en los cuales se han aplicado conceptos y teorías sociológicas a los textos bíblicos; y b) plantea una crítica en la que se valora esta perspectiva, analizando el actual desarrollo metodológico de la sociología del Nuevo Testamento y sopesando sus límites y sus aportes.

El estudio se centra en tres áreas: la historia social del cristianismo del siglo I, el uso de categorías tomadas de la sociología de la religión y la aplicación de la perspectiva de la sociología del conocimiento a la creencia de los primeros cristianos.

Siendo más precisos, en este libro el autor trata los siguientes aspectos:

a) Analiza los métodos aplicados en la sociología bíblica, planteándose si son acertados y si se observa un desarrollo o una estabilización de dichos métodos en la etapa estudiada por el autor.

b) En relación a la historia social, alude al nivel social de los primeros cristianos. 
c) Analiza a continuación la manera cómo se ha utilizado la tipología Iglesia-secta, tomada de la sociología de la religión, para interpretar la vida de los primeros cristianos, retomando el autor el modelo antropológico propio de los movimientos milenaristas que se emplea frecuentemente, así como el modelo propio de los movimientos sectarios.

d) Pondera también la aplicación de la perspectiva de la sociología del conocimiento al estudio de las correlaciones existentes entre las creencias de los primeros cristianos y las distintas situaciones sociales.

e) Yendo finalmente más allá de la descripción de lo que se ha logrado en el ámbito de la sociología bíblica y abordando con mucha precisión lo que puede y no puede hacer la sociología en el ámbito de la teología, subraya el tema de utilidad teológica de la sociología.

Quiero sintetizar aquí algunos puntos importantes en esta obra.

\section{La heterogeneidad social en el cristianismo primitivo}

Algo interesante que se plantea el autor es que no existe una única categoría en la escala social para designar a los primeros cristianos. Por lo tanto, dice él, no se puede considerar que éstos fueran pertenecientes todos ellos a una misma condición social, sino que, por el contrario, los estudios sociológicos nos indicarían la heterogeneidad social de los cristianos del primer siglo. Se debe considerar el nivel social de éstos a partir del sistema de categorías de la sociedad en que vivían, ya sea ésta judía o gentil, oriental u occidental, rural o urbana, provincial o imperial. Se impone en consecuencia la necesidad de distinguir entre cristianos de diferentes tiempos, lugares y contextos sociales para abordar el nivel social de los primeros cristianos.

Se encuentran personajes influyentes entre los primeros cristianos de Jerusalén, personas pudientes entre los helenistas; el mismo apóstol Pablo pertenecía al grupo privilegiado de las familias helenistas que además habían recibido la ciudadanía romana. La iglesia de Corinto, por su parte, incluía algunos intelectuales, políticos y personas de noble ascendencia. Los primeros conversos de muchas iglesias de la diáspora eran personas acaudaladas o destacadas socialmente. Junto a ellas se encontraban también los campesinos y los esclavos rurales quienes formaban las clases más desposeídas de la sociedad.

La heterogeneidad social del movimiento cristiano y la capacidad de unificar intereses sociales muy divergentes en la vida comunitaria ha sido siempre una característica singular de la Iglesia.

Theissen, ese gran sociólogo que ha investigado sobre los grupos sociales en el Nuevo Testamento, nos señala que los discípulos de Jesús no provenían de los niveles más bajos de la sociedad judía (renteros, jornaleros, sirvientes y escla- 
vos), sino que pertenecían a las capas medias formadas por artesanos, pescadores, recaudadores de impuestos y pequeños terratenientes. Esto no quita que viviesen modestamente y frecuentemente con sus apuros económicos. No se debe olvidar que renunciaron a su seguridad económica por seguir a Jesús, abandonando consciente y voluntariamente la propiedad, los vínculos familiares y una posesión socialmente segura.

\section{El cristianismo como movimiento milenarista en sus comienzos}

Otro punto interesante en esta obra es que en ella el cristianismo es considerado como un movimiento milenarista porque responde mejor a este modelo que a otros. El autor recoge los cinco rasgos básicos formulados por Gager que apoyan la inclusión del cristianismo entre los movimientos milenaristas: a) la promesa del inminente advenimiento del cielo sobre la tierra; b) la transformación radical del actual orden social; c) una vida comunitaria que expresa una violenta liberación de las energías emocionales; d) la brevísima duración del movimiento; e) el papel decisivo de un dirigente mesiánico, profético y carismático. Además, este autor demuestra que dichos movimientos surgen en contextos de crisis política, económica y religiosa, como los que se daban en Palestina en tiempos de Jesús. Efectivamente, Palestina tenía amplios sectores de la población políticamente alienados y reprimidos, económicamente empobrecidos y obligados a sentirse como extraños e impuros, cuando tuvo su actividad Jesús de Nazaret, formulando las necesidades y aspiraciones de estas mayorías, ofreciendo una visión del mundo tal como debería ser o sería inmediatamente, aportando nuevos medios de redención que trascendían más allá de la Torá y el culto del templo, criticando al mismo tiempo los viejos valores y medios de acceder al centro sagrado de la realidad. Entre las características sobresalientes de los movimientos milenaristas se pueden mencionar el sentido igualitario de la vida y la ausencia de estructuras fijas; además, la supresión de las diferencias con respecto a la riqueza, al sexo y al parentesco.

La correlación entre los textos neotestamentarios y la situación social en que se escriben

El autor, desde la perspectiva de la sociología del conocimiento, intenta hallar correlaciones entre las expresiones de fe y la estructura o situación social subyacente. Esta correlación se establece entre los textos neotestamentarios analizados y la situación social en que se escriben; por tanto, la correlación puede ser total o parcial, positiva o negativa, sin perder de vista que éste es un proceso dialéctico. Todo ello lleva al autor a advertir que se debe tener muy en cuenta que cada grupo y sociedad constituye una comunidad moral con entidad propia que tiene que ser analizada y comprendida en cuanto tal, con sus propios objeti- 
vos que configuran y rigen su comportamiento social. A esto añade que los resultados de las investigaciones son limitados por la poca cantidad de datos que se tienen y también por el empleo de categorías modernas para estudiar situaciones sociales que están a gran distancia temporal y cultural de nosotros.

En todo caso, afirma Bengt Holmberg, no es posible sostener simplistamente una relación causal entre los grupos y comunidades cristianas con determinadas ideas, ya que la ubicación social por sí misma no puede dar razón de las ideas que en ella surgen. Esto nos lleva a plantear la imperiosa necesidad de iniciar la investigación sociológica del Nuevo Testamento, teniendo un amplio y profundo conocimiento de los datos sociales, sopesando en su justa dimensión las sutilezas y la complejidad de este objeto.

En síntesis, no es posible establecer relaciones puntuales, directas y causales entre la vida social y el pensamiento humano a priori; la realidad es más rica y más compleja.

\section{Autonomía y relación entre la teología y la sociología}

Hay que considerar, en cambio, la autonomía del pensamiento teológico, sin negar la función social que tiene, ya sea la de dar legitimidad a determinadas pautas de comportamiento ya sea la de controlarlas y darles una forma definida.

Desde esta perspectiva, la interrelación que se establece entre la situación social y la teología (inclusive con la tradición) es, en opinión del autor, una interrelación de mutuo influjo y de intercambio dinámico. Lo dicho anteriormente nos ubica en dos planos de conocimiento frente al objeto de la base social de las creencias y las ideas cristianas: la sociología tiene que dar explicaciones sociológicas, no trascendentes, mientras que la teología tiene a Dios como referente y sostiene que existe una causalidad trascendente. Por tanto, los teólogos, dice Bengt Holmberg, pueden utilizar el análisis sociológico como instrumento de información, pero sin olvidar que tanto la teoría sociológica como los resultados de su aplicación no son descripciones neutrales e ingenuas de la realidad.

Sobre la relación entre la sociología y la teología Bengt Holmberg nos dice:

La sociología "explica" la teología dentro de su propio universo, mientras que la teología puede encajar en el marco de sus conocimientos la realidad divina y humana. Esto sirve ya de por sí para relativizar y refutar el imperialismo epistemológico o la tendencia al reduccionismo que se da en estas dos disciplinas. Esta toma de conciencia quizá ayude además al teólogo o al escriturista a insistir serenamente en la importancia de la fe como dimensión peculiar de los textos bíblicos (y para entender el mundo en general, por supuesto) (pp. 199-200).

Hay que decir que uno de los aportes relevantes del estudio sociológico de los textos neotestamentarios, hecho por Holmberg, es no sólo que nos ayuda a 
entender la realidad de la cual nos hablan dichos textos como transfondo, sino que también nos descubre una dimensión del mismo significado del texto y de la realidad. En definitiva, el autor concluye que es imposible la comprensión plena del significado del mensaje de Dios sin comprender su encarnación en una comunidad viva (p. 202).

No cabe duda que esta obra nos ofrece importantes aportes sobre el cristianismo primitivo y que, por lo tanto, vale la pena leerlo para tener una mejor comprensión del compromiso al que está llamado quien se considera cristiano.

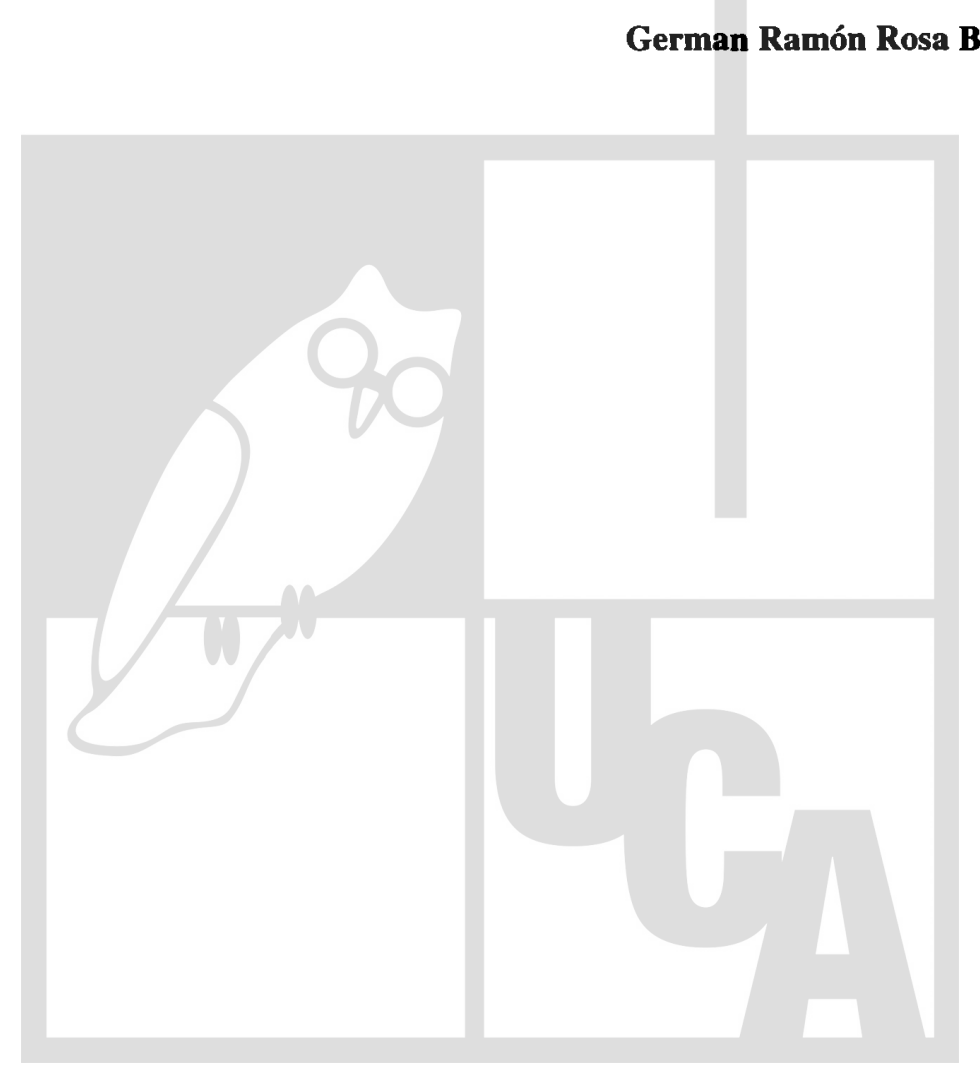

